Egyptian Journal of Aquatic Biology \& Fisheries

Zoology Department, Faculty of Science,

Ain Shams University, Cairo, Egypt.

ISSN $1110-6131$

Vol. 24(6): 135 - 151 (2020)

www.ejabf.journals.ekb.eg

\title{
Differentiation of endangered butter catfish, Ompok bimaculatus populations along the selected habitats of South-western Bangladesh: Evidence from morphological characters
}

\section{Md. Sarower-E-Mahfuj ${ }^{1{ }^{*}}$, Md. Abdus Samad ${ }^{1 ¥}$, Fee Faysal Ahmed ${ }^{2}$, Kazi Shahrukh Elahi ${ }^{3}$,} Md. Ataur Rahman ${ }^{4}$, Ripon Kumar Adhikary ${ }^{1,5}$, Md. Yeamin Hossain ${ }^{4}$

${ }^{1}$ Department of Fisheries and Marine Bioscience, Jashore University of Science and Technology,

Jashore-7408, Bangladesh

${ }^{2}$ Department of Mathematics, Jashore University of Science and Technology, Jashore-7408, Bangladesh

${ }^{3}$ Department of Fisheries Management, Bangladesh Agricultural University, Bangladesh

${ }^{4}$ Department of Fisheries, Faculty of Agriculture, University of Rajshahi, Rajshahi-6201, Bangladesh

5 Environment, Climate and Health Research School of Population Health, The Australian National University, Canberra ACT 2601, Australia

${ }^{¥}$ These authors contributed equally

*Corresponding Author: sa.mahfuz@gmail.com

\section{ARTICLE INFO \\ Article History: \\ Received: June 21, 2020 \\ Accepted: Aug. 29, 2020 \\ Online: Oct 23, 2020}

Keywords:

Meristic, morphometric,

endangered,

Ompok bimaculatus,

Bangladesh

\section{ABSTRACT}

The intraspecific morphological variations of the butter catfish, Ompok bimaculatus has been assessed from two fish farms viz., Chanchra Fish Farm, Jashore (CFFJ) and Fish Seed Complex, Khulna (FSCK) and two natural wetlands viz., Bohni beel, Gopalganj (BBG); Dakatia beel, Khulna (DBK) in south-western part of Bangladesh. A total number of 80 samples were collected comprising 20 individuals from each sampling location. Five meristic characters, 18 morphometric characters and 21 truss-based morphometric characters were measured respectively. Meristic, morphometric and trussbased morphometric characters were exposed to one-way analysis of variance followed by Tukey-HSD post-hoc test at 5\% significance level. Significant differences were observed in two meristic characters viz., CFR and PevFR, and five morphometric and four truss morphometric characters. However, morphometric and truss measurements showed highly intermingled among four populations in discriminant functions (DFs) analysis and discriminant space as well. DFs showed that 6-7, PrDL, HL, PSDL, 1-2, 46, FL, ED, 3-9, 5-6, SnL and 4-5 characters contributed 62.8\% in first DF, while 2-9, HD, 1-9, 2-3, 2-6, 3-6, 3-4, LAB, 3-8, 9-10, IO and MXBLR characters contributed $20.6 \%$ in second DF, and the remaining characters contributed $16.6 \%$ in third DF. In cluster analysis, two distinct clusters were made, where BBG demonstrated a solitary group and FSCK and CFFJ jointly shaped alternative cluster, while DBK population found a subgroup with CFFJ. These results postulate the occurrence of intermingling populations of this species from four aquatic habitats. These morphological discrepancies play an important role in establishing proper decision in order to achieve appropriate management and conservation as well as mass seed production for their future sustainability.

\section{INTRODUCTION}

Knowledge on biological identification at the genus, species and stock levels of aquatic organism plays a vibrant role from numerous perspectives such as evolution, taxonomy, ecology, conservation and management (Kalhoro et al., 2015). Numerous approaches have already been 
developed for recognition of population status of a fish species such as parasites, molecular markers, conventional tags/labels, while morphological strategies is a state-of-art technique with many preferences as for example quick and helpful and has been effectively utilized in many researches regarding phenotypic variations of fishes (Keivany and Mohsen, 2017). Thus, meristic and morphometric characters are frequently used methods in fisheries research for stock identification, stock delineation and/or stock discrimination of a fish species (Cadrin, 2000). Uncovering of morphological changes within fish populaces in its geographical variety may point out the occurrence of stock formation (Agüero and Rodriguez, 2004). Moreover, morphometric characters assume a fundamental part in fisheries inquire which is utilized for looking at ontogenical developments and morphological patterns of populations crosswise over areas (Hossen $\boldsymbol{e t}$ al., 2019). Morphological variety of the species in intraspecific is essentially caused by ecological components (Țălu, 2012). Additionally, synergistic effects of allelic recombination and ecological influences on various growths would produce shape modification amongst populaces (Garrod and Horwood, 1984). To study the shortcomings of conventional morphometric strategies, 'the truss network' study has been progressively utilized in fisheries research with different analyses methods such as univariate, bivariate and multivariate statistics (Cadrin, 2000). According to Cavalcanti et al., (1999), image processing procedures are highly recognized for obtaining external phenotypical features in traditional and truss based morphometrics study. Obtaining appropriate accomplishment of morphological variation and stock identification, a modified box-truss network based on inter connected landmarks recently gained much scientific attention due to its easiness of comprehension, depiction and appropriate quantification of body shape (Rohlf, 1990). Alike landmarks are shared distinct structures amongst biological samples (Bookstein, 1990) which are frequently employed as parallel positions on a target entity that implies in intra and inter populations level (Swain and Foote, 1999). Moreover, relevant research works have given as tabulated form. Furthermore, in our study, we also used one-way analysis of variance of meristic data and discriminant function analysis, cluster analysis of morphometric data to elucidate the intra- and inter-population disparity in butter catfish, Ompok bimaculatus from four selected habitats in the South-Western part of Bangladesh, namely, Chanchra Fish Farm, Jashore (CFFJ); Bohni Baor, Gopalganj (BBG), Dakatia Beel, Khulna (DBK) and Fish Seed Complex, Khulna (FSCK).

Butter Catfish, O. bimaculatus (Hamilton, 1822) belongs to the family Siluridae under order Siluriformes, is a fairly a common species in all freshwaters across Pakistan to Indonesia (Gilani and Rahman, 2005). This species is obtainable in rivers, streams, inundated flood plains and waterbodies throughout Bangladesh (Kostori et al., 2011). Recently, this fish species is frequently cultured in farm levels due to its high market demand and popular food fish for sufficient amounts of protein, lipid, mineral and carbohydrate contents in their muscles (Hei and Sarojnalini, 2012). This species mainly sustains on crustaceans, zooplankton larvae, fish, oligocheates, algae and bottommost detritus in their habitats and regarded as both carnivore (Kibria, 2007; Mishra et al., 2013) and omnivore fish (Arthi et al., 2011). Although, in earlier the abundance of O. bimaculatus was higher in their native environments (Rahman, 2005) than the present times but several anthropogenic effects and overexploitations made by human activities as well as abiotic and biotic factors are the common reasons for declining genetic diversity as well as the resilience of the populations severely (Lewis et al., 2017). Presently, O. bimaculatus is considered as a near threatened species according to IUCN-Bangladesh (2015), and there is a crucial need to allow instant adequate management plan for their right protection and conservation in this area. Currently, there is a scarce knowledge regarding on biology, 
ecology and population dynamics of endangered butter catfish, O. bimaculatus in south-western, Bangladesh. Therefore, taking the above circumstances, the objective of the research work is to identify the meristic and morphometric variations of the fast-depleting $O$. bimaculatus populations from four freshwaters in Bangladesh for its proper ecological conservation as well as management.

\section{MATERIALS AND METHODS}

Sampling of fishes. From each sampling site 20 samples were collected and totally 80 samples were used from four freshwater sources specifically, Bohni Baor, Gopalganj (BBG), Chanchra Fish Farm, Jashore (CFFJ); Fish Seed Complex, Khulna (FSCK) and Dakatia Beel, Khulna (DBK) (Table 1) during the period of October to December by using gill nets. After sampling, fishes were immediately preserved in ice-box and instantly transferred into the laboratory of Fisheries Biology under the department of Fisheries and Marine Bioscience in Jashore University of Science and Technology, Bangladesh for meristic, morphometric studies. To collect sound data, only vigorous and undamaged fish samples were selected for studies.

Counting of meristic characters. Five merestic characters were counted namely, number of dorsal fin rays (DFR), number of caudal fin rays (CFR), number of anal fin rays (AFR), number of pelvic fin rays (PelFR), and number of pectoral fin rays (PecFR) of each specimen by using needles and glass lens. To eliminate human bias all meristic parameters were assembled by the similar person.

Measurement of traditional and truss based morphometric characters. Firstly, the fresh collected samples were thawed by using normal tap water and softly erased the glaze water on the surface of fish body by using soft tissue paper. Secondly, the fish instantly kept on a marked white paper with a labeled scale for taking the digital image from left to right directions by using a digital camera (Cyber-shot DSC-W300, China) (Mahfuj et al., 2019a). Thirdly, all images were retrived from the retrived from the memory stick and then added in tpsDigV.2.1 (Rohlf, 2006) software for measuring the morphometrics characters (Figure 1 and 2).

In this regard, traditional morphometric characters were measured directly by the aid of reference scale. On the other hand, 10 selected landmarks were fixed and eventually 21 interconnected truss distances were measured that ultimately formed a truss box on each image. This interconnected truss box on each sample represented the unique outline of the fish (Strauss and Bookstein, 1982). Finally, all measurements were successively reassigned to SPSS 22 version software for supplementary analysis.

Statistical analysis. To exclude the size variation resulting from morphometric and truss morphometric characters were standardized by using a model developed by Elliott et al. (1995) with modifications.

$\mathrm{M}_{\mathrm{adj}}=\mathrm{M}\left(\mathrm{L}_{\mathrm{S}} / \mathrm{L}_{\mathrm{o}}\right)^{\mathrm{b}}$

Where, M: Unique measurement, $\mathrm{M}_{\mathrm{adj}}$ : Size adjusted measurement, $\mathrm{L}_{\mathrm{o}}$ : Total length of fish, and $\mathrm{L}_{\mathrm{S}}$ :Overall mean of total length for all fish from all samples. Parameter $\mathrm{b}$ was assessed for each measured character from the experimental data as the slope of theregression of $\log \mathrm{M}$ on $\log \mathrm{L}_{\mathrm{O}}$. The effectiveness of size adjustment conversion was deliberated by testing the transformed 
variable and TL by using the aforementioned model. This is why TL was curtailed in the final statistical analysis. Naturally the meristic parameters are counted as self-regulating variable of each specimen (Pinheiro et al., 2005). Consequently, they were measured as raw data (Kahilainen and Østbye, 2006), and finally exposed without modification of the size consequence (Marques $\boldsymbol{e t}$ al., 2006). One-way analysis of variance (ANOVA) with Tukey-HSD post-hoc test at 5\% significance level was considered to test the significance of meristic, traditional and truss measurements. The degree of resemblance of diverse features such as morphometric and truss dimensions amongst the samples and the proportional significance of each dimension for the split-up of the populations were evaluated by discriminant function analysis (DFA). An unweighted pair group (UPGMA) and cluster dendrogram was constructed based on the mean values of morphometric and truss distances data were used. All statistical analyseswere done using SPSS v 22 (SPSS, Chicago, IL,USA).

\section{RESULTS}

The minimum and maximum values of each meristic count ranged from 3 to 4 for DFR, 13 to 22 for CFR, 56 to 75 for AFR, 6 to 9 for PevFR, and 10 to 15 for PecFR among four populations examined with corresponding descriptive statistical parameters (i.e. mean and standard deviation) (Table 2). ANOVA results followed by Tukey-HSD post-hoc test showed that two characters i.e. CFR ( $\mathrm{F}=4.197$; $\mathrm{P}$-value, $0.008<0.05)$ and PevFR ( $\mathrm{F}=4.669$; $\mathrm{P}$-value, $0.005<$ $0.05)$ out of five meristic characters were significantly different whereas DFR ( $\mathrm{F}=0.267, \mathrm{P}-$ value, $0.122>0.05)$, AFR ( $\mathrm{F}=0.727$, P-value, $0.727>0.05)$ and PecFR $(\mathrm{F}=1.997$, P-value, $0.727>0.05)$ found insignificant difference among four populations. The BBG, CFFJ populations resembled each other and highly significant to FSCK while DBK population formed intermediate between BBG, CFFJ and FSCK populations for the character of CFR. Similarly BBG population demonstrated highly significant to CFFJ and DBK populations whereas FSCK population formed intermediate among BBG, CFFJ and DBK populations for the character of PevFR.

Nevertheless, in traditional morphometrics the general descriptive statistics are given in Table 2. However, ANOVA results followed by Tukey-HSD post-hoc test proved that five characters namely, HL ( $\mathrm{F}=7.650$, P-value, $0.000<0.05)$, PsOL $(\mathrm{F}=2.864$, P-value, $0.042<0.05)$, PsDL $(\mathrm{F}=3.100$, P-value, $0.032<0.05)$, HDF $(\mathrm{F}=5.698$, P-value, $0.001<0.05)$ and LJL $(\mathrm{F}=2.693$, P-value, $0.049<0.05)$ found significant differences among the eighteen morphometric characters. The CFFJ and DBK populations demonstrated highly significant differences than BBG and FSCK populations for the character of HL and PsOL. Additionally, the BBG and FSCK populations showed significant heterogeneity than the CFFJ and DBK populations for the character of PsDL. Moreover, BBG and DBK populations showed significant heterogeneities than CFFJ and FSCK populations for the character of HDF. Furthermore, BBG, FSCK and DBK populations demonstrated significant disparity than CFFJ population. On contrary, the remaining thirteen characters of traditional morphometric characters did not show any momentous change in all populations ( $\mathrm{P}$ value $>0.05)$ (Table 2$)$. 
Consequently, in truss morphometric analysis, the general descriptive statistics are given in Table 3. Nevertheless, one-way analysis of variance followed by Tukey-HSD post-hoc test ascertained that four characters namely, 6-7 ( $\mathrm{F}=14.090$, P-value, $0.000<0.05), 2-6(\mathrm{~F}=3.492$, P-value, $0.020<0.05)$, 3-7 ( F = 4.217, P-value, $0.008<0.05)$ and 8-9 ( F = 4.805, P-value, 0.004 $<0.05)$ found significant differences among the twenty one truss morphometric characters. Firstly, BBG and CFFJ populations are resembled to each other and also demonstrated highly significant than DBK and FSCK populations respectively for 6-7 character. Secondly, the BBG, CFFJ and DBK populations resembled to each other and possessed highly significant differences than FSCK population. Thirdly, BBG and CFFJ populations revealed significant differences than the FSCK and DBK populations. Finally, BBG and DBK populations formed significant disparity than the CFFJ and FSCK populations. In order to analyze discriminant function analysis between populations, and the DFA highlighted three discriminant functions (DF1, DF2, and DF3) for traditional morphometrics and truss-network dimensions where, the first DF reported for $62.8 \%$ at eigenvalue 5.186, the second DF reported for $20.6 \%$ at eigenvalue 1.699 and the third DF reported for $16.6 \%$ at eigenvalue 1.375 , respectively among group variability, elucidating $100 \%$ of the total assemblage variability (Table 4). Pooled within-groups correlations between discriminant variables and DFs showed that 6-7, 1-2, 4-6, 3-9, 5-6, 4-5, PrDL, HL, PsDL, FL, ED, SnL contributed to first DF. Similarly, 2-9, 1-9, 2-3, 2-6, 3-6, 3-4, 3-8, 9-10, HDF, HD, LAB, IO and MXBLR contributed to second DF. Side by side, 7-9, 3-7, 10-1, 8-9, 25, 7-8, 3-5, PrOL, SL, LJL, HAF, MXBLL, PsOL and UJL reported to third DF (Table 4).

The bi-plot results derived from both morphometric and truss measurements, the individual of each population was not clearly separated among CFFJ, FSCK and DBK populations with nearly corresponding in changing amounts in the discriminant space while the individual of BBG population showed complete isolation (Figure 3).

Discriminant function analysis showed $98.8 \%$ and $48.8 \%$ original classification and crossvalidation of individuals respectively on the bases of traditional morphometrics and truss network measurements. The proportion of appropriately classified samples was maximum in the BBG (100\%), CFFJ (100\%), FSCK (100\%) followed by the DBK $(95 \%)$ in decreasing order. However, $98.8 \%$ of average original group was correctly classified in original analysis. Conversely, the intermixing rates were observed in all populations using cross-validation analysis showing maximum intermingling rates were observed in DBK (30\%), FSCK (55\%), CFFJ (45\%) and BBG (65\%) and finally $48.8 \%$ of average percentage levels were demonstrated in all populations (Table 5).

A dendrogram prepared by using all morphometrics and truss measurements of each individual data from populations. Two main clusters were generally made, where CFFJ shaped a solitary cluster and FSCK and DBK combindly formed additional cluster. Furthermore DBK formed a sub-cluster with FSCK (Figure 4). 


\section{Figures and Tables}

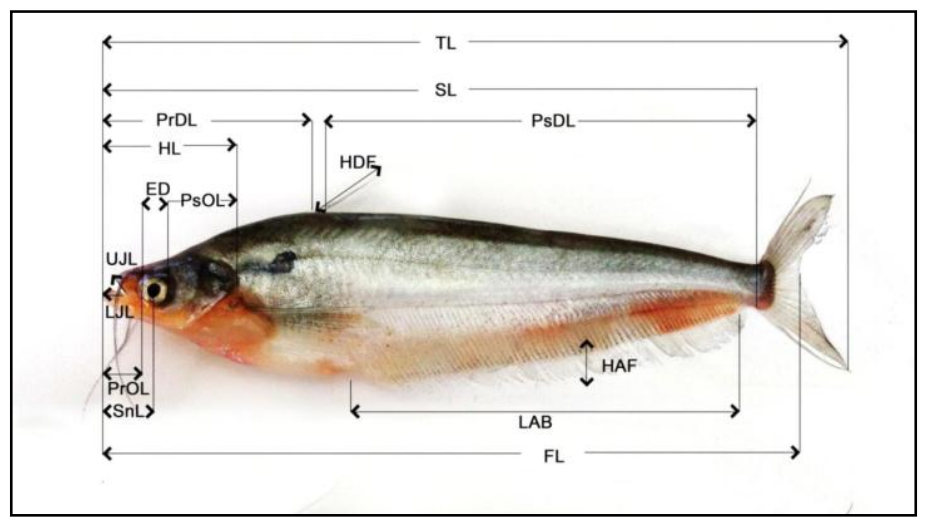

Fig. 1. Nineteen traditional morphometric characters were measured for the analysis in butter catfish, Ompok bimaculatus. TL (total length) - distance from the tip of the upper jaw to the longest caudal fin ray, SL (standard length) - distance from the tip of the upper jaw to the end of the vertebral column, FL (fork length) - distance from the tip of the snout to the end of the fork of caudal fin, HL (head length) - distance from the tip of the snout to the posterior margin of the opercula, HD (head depth) - vertical distance of head, PrOL (pre orbital length) - distance from the tip of the snout to the anterior margin of the eye, PsOL (post orbital length) - distance from the posterior margin of the eye to the end of the operculum, ED (eye diameter) - distance from the pre-orbital length to post-orbital length, SnL (snout length) - distance from the tip of the snout to the anterior position of eye, PrDL (pre-dorsal length) - distance from the snout tip to the anterior base of the dorsal fin, PsDL (post-dorsal length) - distance from the dorsal fin posterior base to the anterior end of the caudal fin, HDF (height of dorsal fin) - horizontal distance of dorsal fin, HAF (height of anal fin) - horizontal distance of anal fin, LAB (length of anal fin base)- horizontal distance from the anterior part to the posterior part of anal fin, UJL (upper jaw length) - distance between the upper snout tip and posterior edge of maxilla, LJL (lower jaw length) - distance between the lower snout tip and posterior edge of mandible, MXBLL (maximum barbell length, Left) - length of the barbel having highest elongation, MXBLR (maximum barbell length, Right) - length of the barbel having highest elongation, IO (inter orbital) - distance between dorsal side of both eyes.

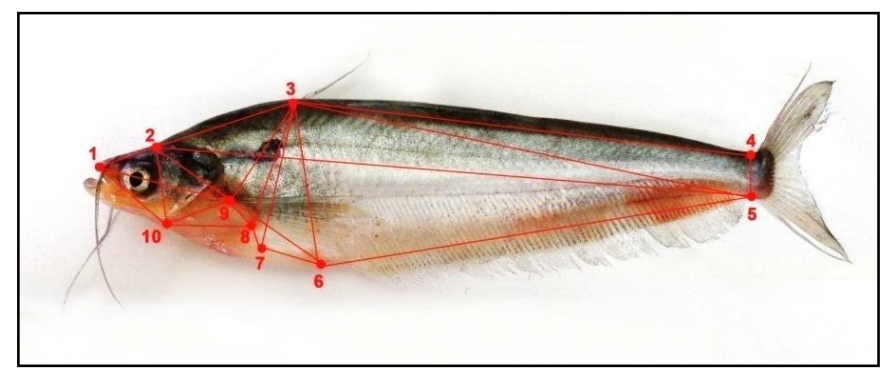

Fig. 2. Position of

the 10 landmarks for assembling the truss morphometric characters on external surface of fish explained as closed red circles. Landmarks describe to (1) anterior tip of snout at upper jaw, (2) most posterior aspect of neurocranium, (3) origin of dorsal fin, (4) anterior attachment of dorsal membrane from caudal fin, (5) anterior attachment of ventral membrane from caudal fin, (6) origin of anal fin, (7) insertion of pelvic fin, (8) origin of pelvic fin, (9) insertion of pectoral fin and (10) insertion point of gill line in ventral side. 


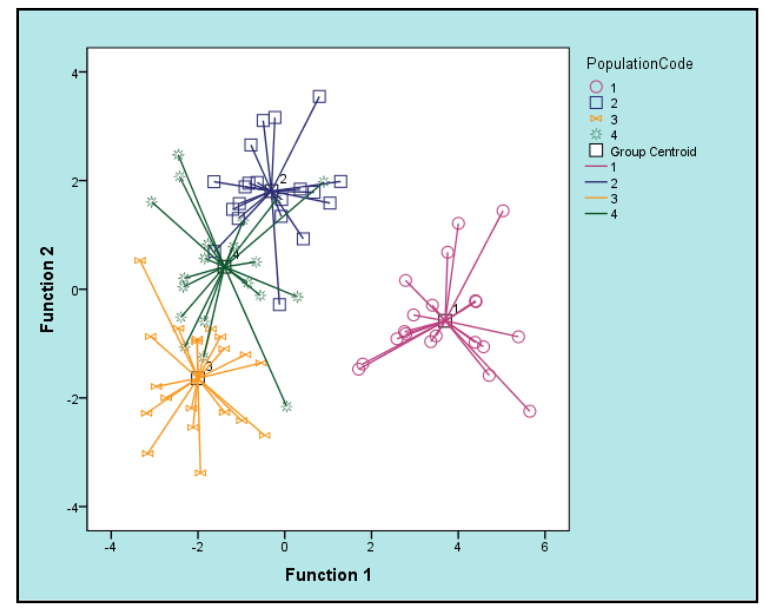

Fig. 3. Bi-plot orientation of individuals from DFA analyses using morphometrics and truss measurements of Ompok bimaculatus populations. Legends are corresponds to 1-BBG: Bohni baor, Gopalgonj; 2-CFFJ: Chanchra Fish Farm, Jashore; 3-FSCK: Fish Seed Complex, Khulna; 4-DBK: Dakatia Beel, Khulna.

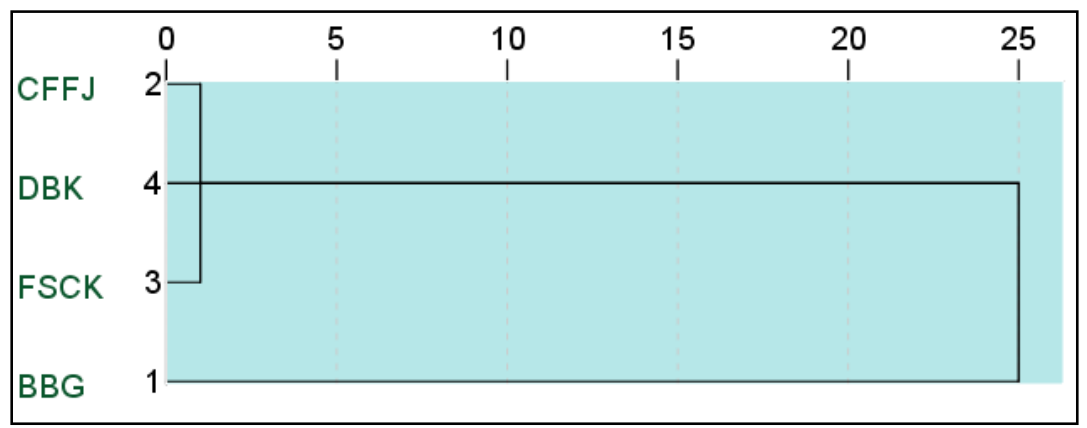

Fig. 4. Dendrogram developed by using morphometric and truss distances of Ompok bimaculatus populations (BBG: Bohni baor, Gopalgonj; CFFJ: Chanchra Fish Farm, Jashore; FSCK: Fish Seed Complex, Khulna; DBK: Dakatia Beel, Khulna) in Bangladeshi freshwaters.

Table 1. Descriptive data and sampling sites of Ompok bimaculatus from South-western Bangladesh

\begin{tabular}{lcccc}
\hline \multicolumn{1}{c}{ Collection sites } & Abbreviation & $\begin{array}{c}\text { No. of } \\
\text { specimens }\end{array}$ & $\begin{array}{c}\text { Mean SL in } \\
\text { cm (SD) }\end{array}$ & $\begin{array}{c}\text { Date of } \\
\text { Collection }\end{array}$ \\
\hline Chanchra Fish Farm, Jashore & CFFJ & 20 & $10.96 \pm 1.03$ & 07.10 .2017 \\
Bohni baor, Gopalgonj & BBG & 20 & $12.94 \pm 1.20$ & 28.10 .2017 \\
Dakatia beel, Khulna & DBK & 20 & $11.45 \pm 1.05$ & 20.11 .2017 \\
Fish Seed Complex, Khulna & FSCK & 20 & $11.19 \pm 1.04$ & 15.12 .2017 \\
\hline
\end{tabular}


Table 2. Descriptive statistics of meristic and morphometric characters of butter catfish Ompok bimaculatus (abbreviations described in materials and methodology part)

\begin{tabular}{|c|c|c|c|c|c|c|c|c|c|c|}
\hline \multirow{2}{*}{$\begin{array}{l}\text { Character } \\
\text { istics }\end{array}$} & \multicolumn{2}{|l|}{ BBG $(n=20)$} & \multicolumn{2}{|l|}{ CFFJ $(\mathbf{n}=20)$} & \multicolumn{2}{|c|}{ FSCK $(n=20)$} & \multicolumn{2}{|l|}{ DBK $(n=20)$} & \multicolumn{2}{|c|}{ ANOVA test } \\
\hline & Mean \pm SD & Min-Max & Mean \pm SD & Min-Max & Mean \pm SD & Min-Max & Mean \pm SD & Min-Max & $\mathbf{F}$ & P-value \\
\hline \multicolumn{11}{|c|}{ Meristic characters } \\
\hline DFR & $3.50 \pm 0.51$ & $3-4$ & $3.55 \pm 0.60$ & $3-4$ & $3.45 \pm 0.60$ & $3-4$ & $3.40 \pm 0.50$ & $3-4$ & 0.267 & 0.849 \\
\hline CFR & $17.45 \pm 1.70^{\mathrm{A}}$ & $15-22$ & $17.00 \pm 1.45^{\mathrm{A}}$ & $15-19$ & $14.95 \pm 3.94^{\mathrm{C}}$ & $13-18$ & $16.50 \pm 1.43^{\mathrm{AB}}$ & $15-19$ & 4.197 & $0.008^{*}$ \\
\hline AFR & $64.55 \pm 3.96$ & $64-75$ & $67.15 \pm 2.30$ & $63-70$ & $66.45 \pm 4.14$ & $56-75$ & $66.55 \pm 3.54$ & $60-72$ & 0.437 & 0.727 \\
\hline PevFR & $8.05 \pm 1.39^{\mathrm{A}}$ & $7-9$ & $7.15 \pm 0.67^{\mathrm{B}}$ & $6-8$ & $7.65 \pm 0.74^{\mathrm{AB}}$ & $6-8$ & $7.10 \pm 0.71^{\mathrm{B}}$ & $6-8$ & 4.669 & $0.005^{*}$ \\
\hline PecFR & $12.80 \pm 1.10$ & $11-15$ & $13.35 \pm 1.30$ & $10-15$ & $12.40 \pm 1.39$ & $10-15$ & $12.60 \pm 1.35$ & $10-15$ & 1.997 & 0.122 \\
\hline \multicolumn{11}{|c|}{ Morphometric characters } \\
\hline SL & $11.72 \pm 0.42$ & $10.94-14.09$ & $11.57 \pm 0.17$ & $9.95-11.64$ & $12.16 \pm 0.87$ & $8.50-13.28$ & $11.78 \pm 0.45$ & $8.36-13.22$ & 2.313 & 0.083 \\
\hline FL & $12.54 \pm 0.29$ & $12.20-14.74$ & $12.10 \pm 0.41$ & $10.02-12.76$ & $2.60 \pm 0.25$ & $8.67-13.88$ & $11.63 \pm 2.47$ & $11.24-13.80$ & 1.304 & 0.279 \\
\hline HL & $2.30 \pm 0.28^{\mathrm{B}}$ & $1.84-2.93$ & $2.47 \pm 0.23^{\mathrm{A}}$ & $2.07-2.91$ & $1.25 \pm 0.12^{\mathrm{B}}$ & $2.20-3.48$ & $2.67 \pm 0.25^{\mathrm{A}}$ & $2.11-3.10$ & 7.650 & $0.000^{*}$ \\
\hline HD & $1.26 \pm 0.11$ & $1.09-1.67$ & $1.35 \pm 0.08$ & $1.20-1.47$ & $0.55 \pm 0.15$ & $0.98-1.58$ & $1.35 \pm 0.26$ & $1.06-2.09$ & 2.253 & 0.089 \\
\hline PrOL & $0.56 \pm 0.10$ & $0.38-0.77$ & $0.58 \pm 0.10$ & $0.40-0.88$ & $0.61 \pm 0.28$ & $0.29-0.90$ & $0.58 \pm 0.11$ & $0.32-0.83$ & 0.939 & 0.426 \\
\hline PsOL & $1.50 \pm 0.27^{\mathrm{B}}$ & $1.14-2.15$ & $1.65 \pm 0.25^{\mathrm{A}}$ & $1.13-2.11$ & $1.50 \pm 0.02^{\mathrm{B}}$ & $1.08-2.34$ & $1.74 \pm 0.23^{\mathrm{A}}$ & $1.31-2.15$ & 2.864 & $0.042 *$ \\
\hline ED & $0.48 \pm 0.02$ & $0.40-0.51$ & $0.49 \pm 0.02$ & $0.46-0.60$ & $0.65 \pm 0.10$ & $0.46-0.60$ & $0.49 \pm 0.02$ & $0.46-0.60$ & 1.414 & 0.245 \\
\hline $\mathrm{SnL}$ & $0.69 \pm 0.09$ & $0.54-0.95$ & $0.68 \pm 0.09$ & $0.47-0.90$ & $0.68 \pm 0.11$ & $0.44-0.83$ & $0.66 \pm 0.12$ & $0.39-0.92$ & 0.942 & 0.424 \\
\hline PrDL & $3.47 \pm 0.80$ & $2.32-4.56$ & $3.41 \pm 0.22$ & $2.85-3.72$ & $3.22 \pm 0.58$ & $2.39-3.56$ & $3.39 \pm 0.27$ & $2.50-3.99$ & 2.047 & 0.114 \\
\hline PsDL & $7.66 \pm 0.66^{\mathrm{A}}$ & $6.88-9.40$ & $7.24 \pm 0.44^{\mathrm{B}}$ & $6.23-8.60$ & $7.53 \pm 0.09^{\mathrm{A}}$ & $5.71-9.11$ & $7.30 \pm 0.31^{\mathrm{B}}$ & $5.33-8.96$ & 3.100 & $0.032 *$ \\
\hline $\mathrm{HDF}$ & $1.43 \pm 0.12^{\mathrm{A}}$ & $1.15-1.64$ & $1.40 \pm 0.14^{\mathrm{B}}$ & $1.02-1.63$ & $1.37 \pm 0.03^{\mathrm{B}}$ & $1.36-1.66$ & $1.52 \pm 0.11^{\mathrm{A}}$ & $1.34-1.68$ & 5.698 & $0.001 *$ \\
\hline HAF & $0.42 \pm 0.05$ & $0.30-0.52$ & $0.42 \pm 0.09$ & $0.27-0.62$ & $0.43 \pm 1.01$ & $0.32-0.43$ & $0.42 \pm 0.06$ & $0.30-0.52$ & 2.289 & 0.085 \\
\hline LAB & $7.46 \pm 0.64$ & $6.35-9.18$ & $7.21 \pm 0.26$ & $6.23-7.61$ & $7.81 \pm 0.06$ & $4.57-9.10$ & $7.13 \pm 0.31$ & $5.24-8.29$ & 1.256 & 0.296 \\
\hline UJL & $0.79 \pm 0.10$ & $0.62-0.99$ & $0.77 \pm 0.09$ & $0.62-0.99$ & $0.79 \pm 0.05$ & $0.66-0.90$ & $0.82 \pm 0.09$ & $0.62-0.97$ & 0.992 & 0.401 \\
\hline LJL & $0.80 \pm 0.10^{\mathrm{A}}$ & $0.65-1.01$ & $0.73 \pm 0.10^{\mathrm{B}}$ & $0.56-0.90$ & $0.86 \pm 0.42^{\mathrm{A}}$ & $0.66-0.80$ & $0.81 \pm 0.10^{\mathrm{A}}$ & $0.58-0.96$ & 2.693 & $0.049 *$ \\
\hline MXBLL & $4.95 \pm 0.32$ & $4.30-5.50$ & $4.94 \pm 0.88$ & $4.00-5.80$ & $4.93 \pm 0.43$ & $4.00-5.80$ & $4.94 \pm 0.35$ & $4.20-5.60$ & 0.869 & 0.461 \\
\hline MXBLR & $4.81 \pm 0.30$ & $4.30-5.40$ & $4.79 \pm 0.52$ & $4.10-6.00$ & $4.80 \pm 0.04$ & $4.20-6.00$ & $4.81 \pm 0.35$ & $4.00-5.60$ & 0.385 & 0.764 \\
\hline IO & $0.97 \pm 0.04^{\mathrm{A}}$ & $0.88-1.10$ & $0.98 \pm 0.17^{\mathrm{A}}$ & $0.80-1.05$ & $0.98 \pm 0.03^{\mathrm{A}}$ & $0.88-1.04$ & $0.97 \pm 0.06^{\mathrm{A}}$ & $0.80-1.04$ & 0.968 & 0.412 \\
\hline
\end{tabular}

* Significant difference at 5\% significant level. Min: Minimum, Max: Maximum. SD: Standard deviation. ANOVA: Analysis of variance (One-way). F: The ratio of between-group variability and within group variability. Means with identical superscript letter are not significantly different for each meristic and traditional variable. Means with different superscripts letter are significantly different for each meristic variable and traditional variable. The acronyms of meristic, traditional morphometrics and population names are described in materials and methods section. 
Table 3. Descriptive statistic results of truss morphometric characters of butter catfish Ompok bimaculatus (abbreviations described in materials and methodology part)

\begin{tabular}{|c|c|c|c|c|c|c|c|c|c|c|}
\hline & \multicolumn{2}{|c|}{ BBG $(n=20)$} & \multicolumn{2}{|c|}{ CFFJ $(n=20)$} & \multicolumn{2}{|c|}{$\operatorname{FSCK}(\mathbf{n}=20)$} & \multicolumn{2}{|c|}{ DBK $(\mathbf{n}=20)$} & \multicolumn{2}{|c|}{ ANOVA test } \\
\hline & Mean \pm SD & Min-Max & Mean \pm SD & Min-Max & Mean \pm SD & Min-Max & Mean \pm SD & Min-Max & $\mathbf{F}$ & P-value \\
\hline \multicolumn{11}{|c|}{ Truss morphometric characters } \\
\hline $1-2$ & $1.59 \pm 0.32$ & $1.35-2.52$ & $1.57 \pm 0.19$ & $1.12-1.71$ & $1.57 \pm 0.26$ & $1.06-2.25$ & $1.57 \pm 0.18$ & $0.94-1.83$ & 1.698 & 0.175 \\
\hline $2-3$ & $1.96 \pm 0.31$ & $1.45-2.73$ & $1.97 \pm 0.29$ & $1.14-2.40$ & $1.97 \pm 0.34$ & $1.06-2.39$ & $1.97 \pm 0.29$ & $1.14-2.62$ & 1.393 & 0.251 \\
\hline $3-4$ & $8.33 \pm 0.34$ & $7.70-9.54$ & $8.32 \pm 0.34$ & $6.82-8.74$ & $8.33 \pm 0.78$ & $5.88-9.17$ & $8.34 \pm 1.24$ & $3.02-8.64$ & 2.525 & 0.064 \\
\hline $4-5$ & $0.73 \pm 0.18$ & $0.56-0.83$ & $0.72 \pm 0.06$ & $0.52-0.77$ & $0.72 \pm 0.08$ & $0.45-0.76$ & $0.73 \pm 0.06$ & $0.44-0.83$ & 1.008 & 0.394 \\
\hline $5-6$ & $7.55 \pm 1.66$ & 7.61-12.93 & $7.67 \pm 0.42$ & $6.50-8.93$ & $7.83 \pm 0.80$ & $5.53-9.52$ & $7.67 \pm 0.31$ & $5.62-9.05$ & 1.048 & 0.376 \\
\hline $6-7$ & $1.24 \pm 0.26^{\mathrm{A}}$ & $1.11-2.81$ & $1.10 \pm 0.22^{\mathrm{A}}$ & $0.75-1.80$ & $0.81 \pm 0.22^{\mathrm{C}}$ & $0.23-1.14$ & $0.94 \pm 0.16^{\mathrm{B}}$ & $0.61-1.09$ & 14.090 & $0.000 *$ \\
\hline $7-8$ & $0.57 \pm 0.13$ & $0.37-.93$ & $0.58 \pm 0.14$ & $0.25-0.82$ & $0.57 \pm 0.13$ & $0.34-0.72$ & $0.57 \pm 0.11$ & $0.38-0.91$ & 0.338 & 0.798 \\
\hline $8-9$ & $0.56 \pm 0.12$ & $0.34-0.88$ & $0.56 \pm 0.10$ & $0.36-0.72$ & $0.57 \pm 0.10$ & $0.19-0.72$ & $0.57 \pm 0.15$ & $0.23-0.87$ & 1.785 & 0.157 \\
\hline $9-10$ & $1.10 \pm 0.31$ & $0.72-2.35$ & $1.10 \pm 0.18$ & $0.71-1.46$ & $1.11 \pm 0.10$ & $0.69-1.22$ & $1.09 \pm 0.14$ & $0.61-1.24$ & 1.692 & 0.176 \\
\hline $10-1$ & $1.67 \pm 0.28$ & $1.22-2.41$ & $1.66 \pm 0.35$ & $1.03-2.99$ & $1.66 \pm 0.26$ & $1.65-2.39$ & $1.67 \pm 0.24$ & $1.25-2.34$ & 0.965 & 0.414 \\
\hline $1-9$ & $2.15 \pm 0.30$ & $1.86-3.01$ & $2.16 \pm 0.16$ & $1.84-2.44$ & $2.17 \pm 0.21$ & $1.52-2.41$ & $2.15 \pm 0.27$ & $1.57-2.87$ & 2.045 & 0.115 \\
\hline $2-5$ & $9.71 \pm 0.69$ & $8.90-11.96$ & $9.70 \pm 0.52$ & $8.22-9.94$ & $9.70 \pm 1.14$ & $7.38-11.83$ & $9.71 \pm 1.83$ & $8.65-11.99$ & 0.459 & 0.712 \\
\hline $2-6$ & $3.23 \pm 0.40^{\mathrm{A}}$ & $2.68-4.94$ & $3.21 \pm 0.17^{\mathrm{A}}$ & $2.46-3.37$ & $2.87 \pm 0.68^{\mathrm{B}}$ & $2.34-3.94$ & $3.25 \pm 0.32^{\mathrm{A}}$ & $2.22-3.89$ & 3.492 & $0.020 *$ \\
\hline $2-9$ & $1.36 \pm 0.29$ & $0.91-2.44$ & $1.37 \pm 0.19$ & $1.17-1.90$ & $1.35 \pm 0.19$ & $0.86-1.81$ & $1.37 \pm 0.34$ & $0.77-3.02$ & 2.435 & 0.071 \\
\hline $3-5$ & $7.92 \pm 0.52$ & $7.69-10.24$ & $7.97 \pm 1.75$ & $6.26-8.64$ & $7.97 \pm 0.92$ & $5.87-9.49$ & $7.96 \pm 0.48$ & $5.84-8.98$ & 1.160 & 0.331 \\
\hline $3-6$ & $2.62 \pm 0.24$ & $2.30-3.37$ & $2.63 \pm 0.09$ & $2.25-2.74$ & $2.68 \pm 0.28$ & $1.93-3.29$ & $2.61 \pm 0.17$ & $1.82-3.05$ & 2.361 & 0.078 \\
\hline $3-7$ & $2.60 \pm 0.23^{\mathrm{A}}$ & $2.29-3.39$ & $2.59 \pm 0.16^{\mathrm{A}}$ & $2.13-2.83$ & $2.40 \pm 0.42^{\mathrm{B}}$ & $1.85-2.93$ & $2.31 \pm 0.34^{\mathrm{B}}$ & $1.37-2.95$ & 4.217 & $0.008 *$ \\
\hline $3-8$ & $2.35 \pm 0.24$ & $1.99-3.22$ & $2.34 \pm 0.18$ & $1.89-2.71$ & $2.35 \pm 0.55$ & $1.32-2.85$ & $2.35 \pm 0.18$ & $1.51-2.95$ & 2.217 & 0.093 \\
\hline $3-9$ & $2.42 \pm 0.27$ & $1.80-3.09$ & $2.41 \pm 0.45$ & $1.71-2.95$ & $2.43 \pm 0.25$ & $1.36-2.77$ & $2.44 \pm 0.25$ & $1.37-2.67$ & 1.009 & 0.394 \\
\hline $8-9$ & $1.59 \pm 0.32^{\mathrm{A}}$ & $0.93-1.59$ & $1.07 \pm 0.15^{\mathrm{B}}$ & $0.74-1.28$ & $1.13 \pm 0.15^{\mathrm{B}}$ & $0.81-1.39$ & $1.26 \pm 0.22^{\mathrm{A}}$ & $0.90-1.69$ & 4.805 & $0.004 *$ \\
\hline $4-6$ & $7.86 \pm 0.31$ & $7.36-10.96$ & $7.87 \pm 0.21$ & $6.60-9.04$ & $7.88 \pm 0.93$ & $5.42-9.72$ & $7.97 \pm 0.43$ & $5.70-9.13$ & 1.640 & 0.187 \\
\hline
\end{tabular}

* Significant difference at 5\% significant level. Min: Minimum, Max: Maximum. SD: Standard deviation. ANOVA: Analysis of variance (One-way). F: The ratio of between-group variability and within group variability. Means with identical superscript letter are not significantly different for each truss morphometric variable. Means with different superscripts letter are significantly different for each truss morphometric variable. The acronyms of meristic, traditional morphometrics and population names are described in materials and methods section. 
Table 4. Within-group correlations results obtained from discriminating variables and discriminant functions (DFs; variables well-arranged by size of correlation within function)

\begin{tabular}{lrrrlrrr}
\hline Characters & Function 1 & Function 2 & Function 3 & Characters & Function 1 & Function 2 & Function 3 \\
\hline \% of Variance & 62.8 & 20.6 & 16.6 & $3-6$ & 0.092 & $0.150^{*}$ & -.090 \\
Cum. variance & 62.8 & 83.4 & 100.0 & $3-4$ & 0.106 & $-0.138^{*}$ & -.078 \\
Eigenvalue & 5.186 & 1.699 & 1.375 & LAB & 0.048 & $-0.127^{*}$ & -.086 \\
\hline $6-7$ & $0.296^{*}$ & 0.245 & -0.006 & $3-8$ & 0.072 & $0.118^{*}$ & -.102 \\
PrDL & $0.266^{*}$ & 0.183 & 0.154 & $9-10$ & 0.091 & $-0.118^{*}$ & -.019 \\
HL & $-0.226^{*}$ & -0.019 & 0.165 & IO & 0.017 & $-0.116^{*}$ & .100 \\
PsDL & $0.147^{*}$ & -0.052 & 0.068 MXBLR & -0.038 & $-0.062^{*}$ & $.032^{*}$ \\
1-2 & $0.113^{*}$ & -0.023 & -0.004 & $7-9$ & 0.066 & -0.111 & $.326^{*}$ \\
4-6 & $0.111^{*}$ & 0.003 & 0.023 PrOL & 0.011 & -0.147 & $.215^{*}$ \\
FL & $0.108^{*}$ & -0.085 & -0.010 SL & 0.061 & 0.079 & $.211^{*}$ \\
ED & $-0.100^{*}$ & 0.035 & -0.038 & $3-7$ & 0.132 & 0.092 & $-.211^{*}$ \\
3-9 & $0.091^{*}$ & 0.050 & -0.047 & LJL & 0.019 & -0.161 & $.209^{*}$ \\
$5-6$ & $0.085^{*}$ & -0.047 & 0.010 & $10-1$ & -0.030 & 0.073 & $.198^{*}$ \\
SnL & $0.072^{*}$ & -0.049 & 0.066 HAF & 0.085 & 0.050 & $.188^{*}$ \\
4-5 & $0.034^{*}$ & 0.003 & 0.010 MXBLL & 0.012 & -0.036 & $.151^{*}$ \\
HDF & -0.128 & $-0.235^{*}$ & 0.182 & PsOL & -0.115 & 0.113 & $.128^{*}$ \\
2-9 & 0.025 & $0.219^{*}$ & 0.090 & $8-9$ & 0.080 & 0.105 & $.117^{*}$ \\
HD & -0.037 & $0.203^{*}$ & 0.091 & UJL & -0.040 & -0.089 & $.112^{*}$ \\
1-9 & 0.000 & $0.183^{*}$ & 0.132 & $2-5$ & -0.012 & 0.011 & $.112^{*}$ \\
2-3 & 0.049 & $0.158^{*}$ & 0.001 & $7-8$ & 0.024 & 0.046 & $-.070^{*}$ \\
2-6 & 0.060 & $0.155^{*}$ & 0.144 & $3-5$ & -0.053 & -0.014 & $.069^{*}$ \\
\hline
\end{tabular}

* Maximum complete correlation between each variable and any discriminant function.

The acronyms of meristic, traditional morphometrics and population names are described in material and methods section.

Table 5. Appropriate classifications of individual of Ompok bimaculatus populations (BBG: Bohni baor, Gopalgonj; CFFJ: Chanchra Fish Farm, Jashore; FSCK: Fish Seed Complex, Khulna; DBK: Dakatia Beel, Khulna) categorized as group-wise and cross-validation method

\begin{tabular}{|c|c|c|c|c|c|}
\hline \multirow[t]{2}{*}{ Population Code } & \multicolumn{4}{|c|}{ Predicted Group Membership } & \multirow[t]{2}{*}{ Total } \\
\hline & BBG & CFFJ & FSCK & DBK & \\
\hline \multicolumn{6}{|l|}{ Original $^{\mathrm{a}}$} \\
\hline $\mathrm{BBG}$ & $20(100 \%)$ & 0 & 0 & 0 & 20 \\
\hline CFFJ & 0 & $20(100 \%)$ & 0 & 0 & 20 \\
\hline FSCK & 0 & 0 & $20(100 \%)$ & 0 & 20 \\
\hline DBK & 0 & $1(5 \%)$ & 0 & $19(95 \%)$ & 20 \\
\hline \multicolumn{6}{|l|}{ Cross-validated $^{\mathrm{b}}$} \\
\hline $\mathrm{BBG}$ & $13(65 \%)$ & $3(15 \%)$ & $2(10 \%)$ & $2(10 \%)$ & 20 \\
\hline CFFJ & $2(10 \%)$ & $9(45 \%)$ & $4(20 \%)$ & $5(25 \%)$ & 20 \\
\hline FSCK & 0 & $3(15 \%)$ & $11(55 \%)$ & $6(30 \%)$ & 20 \\
\hline DBK & $3(15 \%)$ & $6(30 \%)$ & $5(25 \%)$ & $6(30 \%)$ & 20 \\
\hline
\end{tabular}




\section{DISCUSSION}

In the contemporary study, vastly significant morphological disparities of Ompok bimaculatus were observed among four populations. Understanding the proper stock discrimination studies in fishes meristic characters are highly valuable bio-markers and these characters can specify the initial development of a fish species. In case of meristic characters of all samples fluctuated 3-4 rays for DFR, 13-22 for CFR, 56-75 for AFR, 6-9 for PevFR, and 11-15 for PecFR. These findings are completely similar to those findings documented by Rahman, (2005) in O. bimaculatus, Chaklader et al. (2016) in Ompok pabda, Ng and Tan (2004) in O.platyrhynchus and Mahfuj et al. (2019b) in O. pabo. In ANOVA test the P-value displayed significantly difference in two meristic characters in CFR and PevFR among all populations. These significant disparities may be caused by genetic and environmental factors during the period of different ontogenical shifts in their life cycle (Swain et al., 2005). Moreover, meristic counts may be fluctuated by abrupt changes of abiotic factors in water bodies such as temperature gradient, productivity, abundance of microalgae, salinity gradient, radiation and degree of day light (Kashefi et al., 2012). Besides, time alterations during spawning, larval development (Bailey and Gosline, 1955) and developmental rates (Gabriel, 1944) are one of the major crucial factors for meristic variation in within species level. In addition, lotic water fish possesses more anal fins to recover their swimming and locomotion based on the hypothesis developed by Swain and Holtby (1989). Therefore, the following water among four habitats might be a crucial factor for the aforementioned populations, though the current velocity of the water from the selected habitats was not measured. Furthermore, ecological influences and rearing density simultaneously can modify the development of meristic characters and sometimes exposes natural aberrations in their development in varying degrees of aquatic organism (Leary et al., 1991). Additionally, geographical variation is one of the major contributors of changes of meristic characters due to the fluctuations of environmental circumstances (Kashefi et al., 2012; Mahfuj et al., 2017; Gain et al., 2017). Aggressive behavior (Simon et al., 2010) coupled with feeding habits might be an important factor of losing their fins and spines because of carnivorousness (Mishra et al., 2013) and omnivorousness (Sivakami, 1982) feeding pattern of O. bimaculatus. Nonetheless, in this present study no momentous changes were detected in DFR, AFR and PecFR except CFR and PevFR characters due to involvement of similar environmental conditions in four populations, which laterally validate similar number of rays in DFR, AFR and PecFR.

However, the phenotypic flexibility of fish is very high and they adjust rapidly by altering their body maintenance and conduct to natural vicissitudes due to the fluctuations of their habitats as well as their environments. These alterations, eventually, modify their morphology and physiology as well as swimming behavior (Mahfuj et al., 2019c, d). In Bangladeshi water bodies there presumably little natural changes of water quality parameters from place to place. However, because of little natural contrasts, the subsequent morphological contrasts in fish might be small to the point that they may be difficult to recognize with net morpho-meristic characters. Consequently, truss network estimations were utilized in this test. Truss network protocols are an effective maneuver for identifying fish populations (Turan, 2004a). A reasonable structure of morphometric assessments using 2-dimensional illustration of a fish relinquishes the necessity to discover the sorts of parameters for the stock separation (Turan et al., 2004b). However, in the present study, the truss linkage coordination can successfully be utilized to recognize the River and beel populations. For these circumstances, gradually critical distinctions were expected due 
to the 4 absolutely dissimilar habitats viz., two aqua-farms CFFJ and FSCK are cultured, controlled, maintained habitat and the rest two wetlands BBG and DBK are closed water. Influences among the 4 populations varied even if the 1st, 2nd or 3rd DF was measured (Table 4). The 1st DF reported for much more (62.8\%) changeability than ensured the 2nd DF (20.6\%) and the 3rd DF (16.6\%). It is obvious that the $1 \mathrm{st}$ DF elucidates much more variances than the 2nd and 3rd DF. Nevertheless, the 3rd DF is considerable rarer instructive clarifying changes among the populations. The dendrogram engaged in this revision occasioned in 2 clusters and 1 sub-cluster: Two main clusters were mainly formed, where BBG fashioned a single cluster and FSCK and CFFJ combinedly formed another bunch. Moreover DBK formed a sub-cluster with FSCK (Figure 5).

The phenotypic discreteness recommends an immediate connection amongst the degree of morphological discrepancy and topographical partition, which demonstrates that physical objectivity, is a limiting variable for the movement among populations. Turan, (2004a) also established parallel outcomes for Liza abu populations from the three Rivers in Turkey. Morphometric dissimilarities amongst populations are usual meanwhile they are physically sequestered and may be started from plentiful predecessors. Fish are remarkably subtle to usual changes and hurriedly adjust by fluctuating essential external morphological parameters. It is outstanding that morphological charms can indicate high pliancy due to disparities in natural circumstances, for example, food availability and temperature (Allendorf, 1987; Swain et al., 1999). In general, same fish species shows more noticeable fluctuations in morphological features in same habitats than other lives (Wimberger et al., 1992).

\section{CONCLUSION}

The results derived from this research are highly usefull as it will be provided as exemplary paradigm of endangered Ompok bimaculatus populations for further deliberates such as conservation and management strategies in the natural wetlands. More research especially molecular tests of the population levels are required for the superior stock identification for ensuring their sustainability in nature to ensure this endangered species from elimination. It is obvious that the morphometric attributes guide qualities toward recognizing populations is over momentously obsolete. However, the implication of truss network organization with strong statistical data analyses method has been entirely re-shaped the examination of morphometric assortment and eventually has extended the vitality of morphometric investigation for stock identification, nowadays. Moreover, the morphometric strategies are heightening the efficacy of truss-based phenotypic investigation in fish stock recognition to energize the viable exploitation of depleted fishery assets as well as protect the biodiversity.

\section{ACKNOWLEDGEMENTS}

We would like to thank local fishermen for their kind assistance during sample collection. Thanks to World Bank (iDA and IFAD) for the financial support through the research grant "PIU-PBRG-Project ID: 154". Thanks to the Project Implementation Unit (PIU), Bangladesh Agricultural Research Council (BARC) for their kind coordination of the aforementioned research project. 


\section{REFERENCES}

Agüero, J.D.L.C. and Rodríguez, F.J.G. (2004). Morphometric stock structure of the Pacific sardine Sardinops sagax (Jenyns, 1842) off Baja California, Mexico. In Morphometrics (pp. 115-127). Springer, Berlin, Heidelberg.

Akhter, P.; Rahman, K.; Orfi, S.D. and Ahmad, N. (2007). Radiological impact of dietary intakes of naturally occurring radionuclides on Pakistani adults. Food Chem. Toxicol., 45(2): 272-277.

Allendorf, F.W. (1987). Genetics and fishery management. Population Genetics and Fishery Management, 1-19.

Arthi, T.; Nagarajan S. and Sivakumar A.A. (2011). Food and feeding habits of two freshwater fishes, Ompok bimaculatus and O. malabaricus of river Amaravathy, Tamil Nadu. The Bioscan., 6(3): 417-420.

Asaduzzaman, M.; Jahan, I.; Noor, A.R.; Islam, M. M. and Rahman, M. M. (2020). Multivariate morphometric investigation to delineate species diversity and stock structure of mud crab Scylla sp. along the coastal regions of Bangladesh. Aqua Fish., In press.

Başusta, A.; Özer, E.I.; Girgin, H.; Serdar, O. and Başusta, N. (2014). Length-weight relationship and condition factor of Hippocampus hippocampus and Hippocampus guttulatus inhabiting Eastern Black Sea. Pak. J. Zool., 46: 447-450.

Bailey, R.M. and Gosline W.A. (1955). Variation of systematic significance of vertebral counts in the American fishes of the family Percidae. Miscell. Publ. Mus. Zool. Univ. Michigan, 93: 1-44.

Barlow, G.W. (1961). Causes and significance of morphological variation in fishes. Syst. Biol., 10:105-117.

Beacham, T.D.; Murray, C.B. and Withler, R.E. (1989). Age, morphology, and biochemical genetic variation of Yukon River Chinook salmon. Trans. Am. Fish. Soc. 118: 46-63.

Booke, H.E. (1981). The conundrum of the stock concept - are nature and nurture definable in fishery science?. Can. J. Fish. Aquat. Sci., 38(12): 1479-1480.

Bookstein, F.L. (1990). Visualizing Biological Shape Differences. Visualization in Biomedical Computing. Proceedings of the First Conference on IEEE.

Bookstein, F.L. (1991). Morphometric Tools for Land Mark Data. Geometry and Biology. Cambridge Univ. Press.

Cadrin, S.X. (2000). Advances in morphometric identification of fishery stocks - Rev. Fish. Biol. Fisher., 10: 91-112.

Cavalcanti, M.J.; Monteiro, L.R. and Lopes, P. (1999). Landmark-based morphometric analysis in selected species of serranid fishes (Perciformes: Teleostei). Zool. Stud., 38: 287-294.

Chaklader, M.R.; Siddik, M.A.B.; Hanif, M.A.; Nahar, A.; Mahmud S. and Piria, M. (2016). Morphometric and meristic variation of endangered pabda catfish, Ompok pabda (Hamilton-Buchanan, 1822) from southern coastal waters of Bangladesh. Pak. J. Zool., 48(3): 681-687.

Chen, J.; Guo, J.; Wang, Z. Q. and Wang, W. M. (2020). Morphological variation among the four Megalobrama species inferred by X- ray photography. Aqua. Res., In press.

Dwivedi, A.K. (2020). Differentiating three Indian shads by applying shape analysis from digital images. J. fish. Biol., 96(6): 1298-1308. 
Dwivedi, A. K., Sarkar, U. K., Mir, J. I., Tamot, P. and Vyas, V. (2019). The Ganges basin fish Cirrhinus mrigala (Cypriniformes: Cyprinidae): detection of wild populations stock structure with landmark morphometry. Rev. Biol. Trop., 67(3): 541-553.

Elliott, N.G.; Haskard, K. and Koslow, J.A. (1995). Morphometric analysis of orange roughy (Hoplostethus atlanticus) off the continental slope of southern Australia. J. Fish. Biol., 46(1): 202-220.

Elahi, N.; Yousuf, F.; Tabassum, S.; Hossain, M.Y.; Hossen, M.; Nawer, F. and Rahman, M. (2017). Life-history Traits of the Blacktrip sardinella, Sardinella melanura (Clupeidae) in the Gwadar, Balochistan Coast, Pakistan. Indian J. Mar. Sci., 46(1): 397404.

Gain, D.; Mahfuj, M.S.; Huq, K.A.; Islam, S.S.; Minar, M.H.; Goutham-Bharathi, M.P. and Das, S.K. (2017). Landmark-based morphometric and meristic variations of endangered mrigal Carp, Cirrhinus cirrhosus (Bloch 1795) from wild and hatchery stocks. Sains Malay., 46(5): 695-702.

Garrod, D. and Horwood, J. (1984). Reproductive strategies and the response to exploitation. In: Potts, G.W., Wootton Fish, R.J. (Eds.), Fish Reproduction. Academic Press, New York, pp. 367-384.

Gilani, A.H. and Atta-ur-Rahman. (2005). Trends in ethnopharmacology. J. Ethnopharmacol., 100(1-2): 43-49.

Gupta, D.; Dwivedi, A. K. and Tripathi, M. (2018). Taxonomic validation of five fish species of subfamily Barbinae from the Ganga river system of northern India using traditional and truss analyses. PloS one, 13(10): e0206031.

Hamilton, F. (1822). An account of the fishes found in the river Ganges and its branches. Printed for A. Constable and company.

Hanif, M. A.; Siddik, M. A.; Islam, M. A.; Chaklader, M. R. and Nahar, A. (2019). Multivariate morphometric variability in sardine, Amblygaster clupeoides (Bleeker, 1849), from the Bay of Bengal coast, Bangladesh. J. Basic Appl. Zool., 80(1): 53.

Ihssen, P.E.; Booke H.E.; Casselman, J.M.; McGlade, J.M.; Payne, N.R. and Utter, F.M. (1981). Stock identification: materials and methods. Can. J. fish. Aquat. Sci., 38(12): 1838-1855.

Hei, A. and Sarojnalini, C. (2012). Proximate composition, macro and micro mineral elements of some smoke-dried hill stream fishes from Manipur, India. Nat. Sci.,10(1): 59-65.

Hossen, M.A,; Paul, A.K,; Hossain, M.Y,; Ohtomi, J,; Sabbir, W,; Rahman, O,; Jasmin, J,; Khan, M.N,; Islam, M.A,; Rahman, M.A,; Khatun, D. and Kamaruzzaman, S. (2019). Estimation of biometric indices for Snakehead Channa punctata (Bloch, 1793) through Multi-model Inferences. Jordan J Biol Sci,12(2): 197-202.

Hubbs, C.L. (1922). Variations in the number of vertebrae and other meristic characters of fishes correlated with the temperature of water during development. Am. Nat., 56: 360372.

IUCN, Bangladesh. (2015). Red List of Bangladesh. Volume 5: Freshwater Fishes. Dhaka, Bangladesh: IUCN, International Union for Conservation of Nature, Bangladesh Country Office.

Kahilainen K. and Østbye, K. (2006). Morphological differentiation and resource polymorphism in three sympatric whitefish Coregonus lavaretus (L.) forms in a subartic lake. J. Fish Biol., 68: 63-79. 
Kashefi, P.; Bani A. and Ebrahimi, E. (2012). Morphometric and meristic variations between non-reproductive and reproductive kutum females (Rutilus frisiikutum, Kamensky, 1901), in the southwest Caspian Sea. Ital. J. Zool., 79(3): 337-343.

Keivany, Y. and Mohsen, A.R.A.B. (2017). Geometric morphometric comparison of trout barb, Capoeta trutta (Teleostei: Cyprinidae) in the Tigris River basin. Iran. J. Ich., 4(3): 220230.

Kalhoro, M.A.; Liu Q.; Valinassab, T.; Waryani, B.; Abbasi, A.R. and Memon, K.H. (2015). Population Dynamics of Greater Lizard fish, Saurida tumbil from Pakistani waters. Pak. J. Zool., 47: 921-931.

Khan, M.A.; Miyan, K. and Khan, S. (2013). Morphometric variation of snakehead fish, Channa punctatus, populations from three Indian rivers. J. Appl. Ich., 29(3): 637-642.

Khan, M.A. and Nazir, A. (2019). Stock delineation of the long-whiskered catfish, Sperata aor (Hamilton 1822), from River Ganga by using morphometrics. Mar. Fresh. Res., 70(1): 107-113.

Kibria, G. (2007). Formalin and Fish Trade in Bangladesh-Human and Environmental Risks. News article retrieved from http://www.sydneybashibangla.com [Accessed on February 19, 2018].

Kostori, F.A.; Parween, S. and Islam, M.N. (2012). Availability of small indigenous species (SIS) of fish in the Chalan Beel-the largest wetland of Bangladesh. Raj. Uni. J. Zool., 30: 67-72.

Lindsey, C.C. (1988). 3 Factors controlling meristic variation. In: Hoar, W.S., Randall, D.J. (Eds.), Fish Physiology - Academic Press, pp. 197e274.

Leary, R.F.; Allendorf, F.W. and Knudsen, K.L. (1991). Effects of rearing density on meristics and developmental stability of rainbow trout. Copeia, 44-49.

Lewis, J.S.; Farnsworth, M.L.; Burdett, C.L.; Theobald, D.M.; Gray, M. and Miller, R.S. (2017). Biotic and abiotic factors predicting the global distribution and population density of an invasive large mammal. Sci. Rep., 7: 44152.

Mahfuj, M.S.; Ashraful, A.; Parvez, I.; Minar, M.H. and Samad, M.A. (2017). Morphological variations of Labeo bata populations (Teleostei: Cyprinidae) in six rivers of Bangladesh: a landmark-morphometric contribution. Iran. J. Ich., 4(3): 270-280.

Mahfuj, M.S.; Khatun, A.; Boidya, P. and Samad, M.A. (2019a). Meristic and morphometric variations of barred spiny eel Macrognathus pancalus populations from Bangladeshi freshwaters: an insight into landmark-based truss network system. Cro. J. Fish., 77(1): 718.

Mahfuj, M.S.; Hossain, M.F.; Jinia, S.S. and Samad M.A. (2019b). Meristic and morphometric variations of critically endangered butter catfish, Ompok pabo inhabiting three natural sources. Int. J. Bio., 14(4): 518-527.

Mahfuj, M.S.; Rahman, M.M.; Islam, M.; Samad, M.A.; Paul, A.K. and Adhikary, R.K. (2019c). Landmark-based morphometric and meristic variations of freshwater garfish, Xenentodon cancila from four natural stocks of South-Western Bangladesh. J. Adv. Vet. Anim. Res., 6(1): 117-124.

Mahfuj, M.S.; Rahman, S. and Samad, M.A. (2019d). Landmark-based Truss Morphometrics Delineate the Stock Structure of Lepidocephalichthys guntea. J. Fish. Aquat. Sci., 14: 2532.

Marques, J.F.; Teixeira, C.M. and Cabral, H.N. (2006). Differentiation of commercially important flatfish populations along the Portuguese 
coast: evidence from morphology and parasitology. Fish. Res., 81: 293-305.

McHugh, J.L. (1954). The influence of light on the number of vertebrae in the grunion, Leuresthes tenuis. Copeia, 1954: 23-25.

Mir, J.I.; Sarkar, U.K.; Dwivedi, A.K.; Gusain, O.P. and Jena, J.K. (2013). Stock structure analysis of Labeo rohita (H amilton, 1822) across the Ganga basin (India) using a truss network system. J. Appl. Ich., 29(5): 1097-1103.

Melvin, G.D.; Dadswell, M.J. and McKenzie, J.A. (1992). Usefulness of meristic and morphometric characters in discriminating populations of American shad (Alosa sapidissima) (Ostreichthyes: Clupeidae) inhabiting a marine environment. Can. J. Fish. Aquat. Sci., 49: 266-280.

Mir, J.I.; Saxena, N.; Patiyal, R.S. and Sahoo, P.K. (2015). Phenotypic differentiation of Barilius bendelisis (Cypriniformes: Cyprinidae) in four rivers from Central Indian Himalaya. Rev. Biol. Trop., 63(1): 165-173.

Mishra, S.K.; Sarkar, U.K.; Trivedi, S.P.; Mir, J.I. and Pal, A. (2013). Biological parameters of a silurid catfish Ompok bimaculatus (Bloch, 1794) from River Ghaghara, India. J. Env. Biol., 34: 1013-1017.

Miyan, K.; Khan, M.A.; Patel, D.K.; Khan, S. and Ansari, N.G. (2016). Truss morphometry and otolith microchemistry reveal stock discrimination in Clarias batrachus (Linnaeus, 1758) inhabiting the Gangetic river system. Fish. Res., 173: 294-302.

Ng, H.H. and Tan, H.H. (2004). Ompok platyrhynchus, a new silurid catfish (Teleostei: Siluridae) from Borneo. Zootaxa, 580(1): 1-11.

Pinheiro, A.; Teixeira, C.M.; Rego, A.L.; Marques, J.F. and Cabral, H. N. (2005). Genetic and morphological variation of Solea lascaris (Risso, 1810) along the Portuguese coast. Fish. Res., 73: 67-78

Pawson, M.G. (1995). Biogeographical identification of English Channel fish and shellfish stocks. Fish. Res. Tech. Rep. Maff., 99:1-72.

Perazzo, G.X.; Corrêa, F.; Calviño, P.; Alonso, F.; Salzburger, W. and Gava, A. (2019). Shape and size variation of Jenynsia lineata (Jenyns 1842) (Cyprinodontiformes: Anablepidae) from different coastal environments. Hydrobiologia, 828(1): 21-39.

Rahman, A.K.A. (2005). Freshwater fishes of Bangladesh, $2^{\text {nd }}$ edition, Zoological Society of Bangladesh, Department of Zoology, University of Dhaka, Dhaka-1000, pp. 187-188.

Rahman, M.M.; Sharker, M.R.; Sumi, K.R.; Alam, M.A. and Hossen, M.S. (2014). Landmark-based morphometric and meristic variations of stinging catfish, Heteropneustes fossilis (Bloch) among three isolated stocks, the old Brahmaputra River and the Tanguar haor and a hatchery. Int. J. Fish. Aquat. Stud., 1: 163-170.

Rohlf, F.J. (1990). Morphometrics. Annu. Rev. Ecol. Syst. In: Rohlf, F.J., 2004. TpsDig-Thin Plate Spline Digitise, Version 1.4 [Computer software]. Stony Brook: Dept. Ecology and Evolution, State Univ, New York, pp. 299-316.

Rohlf, F.J. and Marcus, L.F. (1993). A revolution morphometrics - Trends Ecol. Evol. 8: 129132.

Rohlf, F.J. (2006). tpsDig 2.1. Stony Brook, NY: Department of Ecology and Evolution, State University of New York.

Shao, Y.; Wang, J.; Qiao, Y.; He, Y. and Cao, W. (2007). Morphological variability between wild populations and inbred stocks of a Chinese minnow, Gobiocypris rarus. Zool. Sci., 24(11): 1094-1102. 
Sivakami, S. (1982). On the biology of Ompok bimaculatus (Bloch) from Bhavanisagar Reservoir (Tamil Nadu) - Geobios New Reports, 1(1\&2): 111-119.

Skillman, R.A. (1989). Status of Pacific Billfish stock. In: Troud RH (ed) Planning the future of billfishes: Research and management in the 90's and beyond. Fishery and stock synopses, data needs and management (Part 1). Marine Recreation Fisheries Series 13, KailuaKona, Hawaii, pp 175-195.

Solomon, S. G.; Okomoda, V. T. and Ogbenyikwu, A. I. (2015). Intraspecific morphological variation between cultured and wild Clarias gariepinus (Burchell) (Clariidae, Siluriformes). Fish. Aqua. Life, 23(1): 53-61.

Stearns, S.C. (1983). A natural experiment in life-history evolution: field data on the introduction of mosquitofish (Gambusia affinis) to Hawaii. Evolution, 37: 601-617.

Strauss, R.E. and Bookstein, F.L. (1982). The Truss: Body Form Reconstructions in Morphometrics - Syst. Biol. 31(2): 113-135.

Simon, K.D.; Bakar Y.; Temple, S.E. and Mazlan, A.G. (2010). Morphometric and meristic variation in two congeneric archer fishes Toxotes chatareus (Hamilton 1822) and Toxotes jaculatrix (Pallas 1767) inhabiting Malaysian coastal waters. J. Zhejiang Univ. Sci. B. 11(11): 871-879.

Swain, D.P. and Holtby L.B. (1989). Differences in morphology and behaviour between juvenile coho salmon (Oncorhynchus kisutch) rearing in lake and in its tributary stream. Can. J. Fish. Aquat. Sci., 46: 1406-1414.

Swain D.P. and Foote C.J. (1999). Stocks and chameleons: the use of phenotypic variation in stock identification. Fish. Res., 43: 113-128.

Swain, D.P.: Hutchings, J.A. and Foote C.J. (2005). Environmental and genetic influences on stock identification characters. In: Cadrin, S.X., Friedland, K.D., Waldman, J.R. (Eds.), Stock Identification Methods: Applications in Fishery Science. Elsevier, Amsterdam.

Talwar, P.K. and Jhingran, A.G. (1991). Inland fishes of India and adjacent countries, Vol. 2, Oxford \& IBH Publishing Co. New Delhi, pp. 612-613.

Ţălu, S. (2012). Texture analysis methods for the characterisation of biological and medical images. Extreme Life, Biospeology \& Astrobiology, 4(1): 8-12.

Turan, C.: Ergüden, D.; Gurlek, M. and Turan, F. (2004a). Genetic and morphologic structure of Liza abu (Heckel, 1843) populations from the rivers Orontes, Euphrates and Tigris. Tur. J. Vet. Ani. Sci., 28(4): 729-734.

Turan, C.; Ergüden, D.; Gürlek, M.; Basusta, N. and Turan, F. (2004b). Morphometric structuring of the anchovy (Engraulis encrasicolus L.) in the Black, Aegean and Northeastern Mediterranean Seas. Tur. J. Vet. Ani. Sci., 28(5): 865-871.

Vladykov, V.D. (1934). Environmental and taxonomic characters of fishes. Trans. R. Can. Inst., 20: 99-140.

Wimberger, P.H. (1992). Plasticity of fish body shape. The effects of diet, development, family and age in two species of Geophagus (Pisces: Cichlidae). Biol. J. Linn. Soc., 45(3): 197218. 